\title{
Adolescent pregnancies: complications, birth outcomes and the possible solutions
}

\author{
Tayfur Çift ${ }^{1}$, Engin Korkmazer ${ }^{1}$, Muzaffer Temur ${ }^{1}$, Berk Bulut ${ }^{2}$, Bariş Korkmaz ${ }^{3}$, \\ Onur Ozdenoğlu ${ }^{1}$, Cem Akaltunn ${ }^{1}$, Emin Üstünyurt ${ }^{1}$ \\ ${ }^{1}$ Bursa Yuksek Ihtisas Training And Research Hospital, Bursa, Turkey \\ ${ }^{2}$ Istanbul Private Live Hospital, Istanbul, Turkey \\ ${ }^{3}$ Mardin Midyat State Hospital, Mardin, Turkey
}

\begin{abstract}
Objectives: In this study we aim to evaluate antenatal, perinatal and postnatal outcomes and complications of adolescent pregnancies, as well as to discuss the social and psychological consequences of these pregnancies.

Material and methods: We compare a total of 243 pregnant women at age 14-18 years to a vast control group at age 19-36 who all delivered at Bursa Yüksek Ihtisas Training and Research Hospital between years 2005-2014.

Results: Antenatal care (folic acid supplementation, pre-conception counseling) was significantly higher in adolescent pregnancy group. Unplanned pregnancy rate was significantly higher in in study group $(p<0.001)$. Preterm delivery (before $37^{\text {th }}$ week) ratio was statistically higher in pregnancy complications.

Conclusions: Adolescent pregnancy is a social entity which should be regulated and prevented by legal measures. Planned pregnancies should be promoted and the public should be educated and informed about the Hazards of adolescent pregnancies. Press institutions, public broadcasting services support the efforts to decrease adolescent pregnancies.
\end{abstract}

Key words: adolescent pregnancy, social results, education, prevention

\section{INTRODUCTION}

Adolescent pregnancy has both physiological and psychological impact on individuals and impairs their well-being profoundly. Such pregnancies are more common in developing countries and the risk of complications is significantly higher compared to adult pregnancies.

Adolescent pregnancies yield several maternal and fetal problems. Maternal mortality, nutritional issues, economic and social problems, as well as depression, abuse and a tendency to be involved in criminal acts is observed more frequently in pregnant adolescents than adults. Furthermore, adolescent pregnancies are more often complicated with prematurity, IUGR, fetal death, abortion, chronic fetal distress, malformation, placental abruption and lead to more operative deliveries compared to adult age population [1-3].

\section{OBJECTIVES}

In this study we aim to evaluate adverse outcomes and complications of adolescent pregnancies in a group of Turkish women, as well as to discuss the social and psychological repercussions of such condition in Turkish society.

\section{MATERIAL AND METHODS}

This is a retrospective cohort study. Medical records of pregnant women under 18 who delivered at Bursa Yüksek Ihtisas Training and Research Hospital between years 2005-2014 were reviewed and data was compared with control group at age 19-36 who delivered in the same facility during same time period. The study group comprised of 243 women who, according to medical records, were under 18 at the time of conception. The control group is composed of 2738 pregnant women at age between 19 and 
36 years old that delivered during the same period in the same healthcare facility.

The inclusion criteria for the study group were as follows: age under 18 at the time of conception, singleton pregnancy, being healthy before pregnancy, attending regular pregnancy visits at least 8 times throughout the pregnancy, delivering at Bursa Yüksek Ihtisas Research and Training Hospital. Exclusion criteria were: age over 18 at the time of conception, having a multiple pregnancy, discontinuing periodic antenatal visits and delivering at any other healthcare institution.

Inclusion criteria for the control group were: age of at least 19 at the time of conception, singleton pregnancy, being healthy before pregnancy, having conceived without the help of any assisted reproductive techniques, attending regular pregnancy visits at least 8 times throughout the pregnancy, delivering at our hospital. Exclusion criteria were: multiple pregnancy, conceiving by ART techniques, having a chronic medical condition before conception, failure to attend at least 8 periodic antenatal visits at our hospital or delivering elsewhere.

Patient data including age, gravidity, and parity, number of abortions, mode of delivery, perinatal problems and postpartum complications was recorded. Regarding newborns, data was collected including sex, height, birth weight, head circumference and APGAR scores at $1 \mathrm{~min}$ and $5 \mathrm{~min}$. Additional information concerning resuscitation and/or neonatal intensive care unit events were recorded when such circumstance had occurred.

Primary outcomes were: birth weight, gestational week at delivery and mode of delivery (vaginal or cesarean); secondary outcomes were: maternal complications during pregnancy or during delivery (such as preeclampsia or diabetes), neonatal intensive care requirement and NICU stay.
Statistical analyses were performed using IBM SPSS (Statistical Package for Social Sciences) 20.0 (IBM, Armonk, NY). Normality of distributions was checked by Kolmogorov-Smirnov test, variables with normal distribution were analyzed using independent samples t-test, Anova; Wilcoxon signed rank test, Mann-Whitney $U$ test and Kruskal-Wallis test were used for non-parametric variables. Linear and logistic regression was used for regression analyses where appropriate. Probabilities smaller than 0.5 were considered as statistically significant.

\section{RESULTS}

A total of 243 pregnant adolescent women at age 14-18 were compared to a group of 2738 pregnant women at age 19-36, all of whom delivered in the same facility. Characteristics of the adolescent pregnancy group and the control group are given in Table 1. Mean age at delivery was 17.2 years old for the adolescent group and 25.2 years old for the control group. There was an evident statistically significant difference between the two groups. Regarding to marital status, being married or not married at time of pregnancy is more common in the adolescent group ( $p<0.001)$. Quite expected, unplanned pregnancy rate in the study group is higher than in the control group and the difference is statically significant $(p<0.001)$. Maternal weight during pregnancy in the study group is less than the control group and the difference is statically significant $(p<0.001)$. The adolescent and control group perinatal outcomes are listed in Table 2. It shows that there is no statistical difference in mode of delivery, whether vaginal or cesarean section $(C / S)$. When it comes to indications for a $C / S$, the only statistically significant difference between the two groups is previous uterine scar that is more frequent in the control

Table 1. Characteristics of the adolescent pregnancies and control groups

\begin{tabular}{|l|c|c|}
\hline & Adolescent group (n= 243) & Control group (n= 2738) \\
\hline Maternal age at delivery, range (years) & $17.2(14-18)$ & $25.2(19-34)$ \\
\hline Age $\leq 15$ years (\%) & $28(11.5)$ & - \\
\hline Age 16-18 years (\%) & $215(88.5)$ & $1558(56.9)$ \\
\hline Nulliparity (\%) & $155(63.8)$ & $41(1.5)$ \\
\hline Marital status, single (\%) & $15(6.2)$ & $764(27.9)$ \\
\hline Unplanned pregnancy (\%) & $169(69.6)$ & $7.1(7-22)$ \\
\hline Mean age of gestation at first visit, range (weeks) & $11.3(8-31)$ & $887(32.4)$ \\
\hline Preconception supplementary folic acid use (\%) & $27(11.1)$ & $<.001$ \\
\hline Prenatal supplementary folic acid use (\%) & $122(50.0)$ & $1807(66.0)$ \\
\hline Smoking & $11(4.5)$ & $181(5.3)$ \\
\hline Pre-pregnancy BMl* & $<.05$ \\
\hline Maternal weight gain during pregnancy [kg] & $20.3 \pm 3.6$ & $22.5 \pm 3.6$ \\
\hline
\end{tabular}

*BMl — body mass index, calculated as weight $(\mathrm{kg}) /$ height $\left(\mathrm{m}^{2}\right)$. Data are expressed as $\mathrm{n}(\%)$, or mean $\pm \mathrm{SD}$ except where otherwise noted. The mean difference is significant at the .05 level 
Table 2. Comparison of the perinatal outcomes of the adolescent and control groups

\begin{tabular}{|c|c|c|c|c|}
\hline Variable & Adolescent group $(n=243$ ) & Control group $(n=2738)$ & $\mathbf{P}$ & Odds ratio $\left(95 \% \mathrm{Cl}^{*}\right)$ \\
\hline \multicolumn{3}{|l|}{ Mode of delivery } & 0.17 & $0.87(0.71-1.06)$ \\
\hline Vaginal & $172(70.8)$ & $1791(65.4)$ & & \\
\hline$C / S^{* *}$ & $71(29.2)$ & 947 (34.6) & & \\
\hline $\mathrm{PPH}^{* * *}$ after vaginal delivery & $4(1.64)$ & $49(1.79)$ & 0.73 & $0.88(0.43-1.81)$ \\
\hline $\mathrm{PPH}$ after $\mathrm{C} / \mathrm{S}$ & $2(0.82)$ & $25(0.91)$ & 0.96 & $0.84(0.29-2.45)$ \\
\hline C/S indications & Adolescent group $(n=71)$ & Control group $(n=947)$ & & \\
\hline Previous uterine scar & $12(16.9)$ & $341(36.0)$ & $<.001$ & $0.31(0.20-0.48)$ \\
\hline Failure to progress or $C P D^{* * * *}$ & $31(43.7)$ & $320(33.8)$ & 0.005 & $1.76(1.23-2.51)$ \\
\hline Fetal distress & $18(25.3)$ & $164(17.3)$ & 0.224 & $1.30(0.84-2.00)$ \\
\hline Malpresentation & $6(8.5)$ & $60(6.4)$ & 0.320 & $0.59(0.40-1.58)$ \\
\hline Macrosomia & $3(4.2)$ & $35(3.7)$ & 0.355 & $1.71(0.34-1.46)$ \\
\hline Placenta previa & $1(1.4)$ & $22(2.3)$ & 0.88 & $0.82(0.63-1.06)$ \\
\hline Eclampsia & - & $2(0.2)$ & - & - \\
\hline
\end{tabular}

${ }^{*} \mathrm{Cl}$ - confidence interval; ${ }^{* *} \mathrm{C} / \mathrm{S}$ - cesarean section; ${ }^{* * * \mathrm{PPH}}$ - postpartum hemorrhage; ${ }^{* * * *} \mathrm{CPD}$ - cephalopelvic disproportion

Table 3. Multiple logistic regression analysis of antenatal complications

\begin{tabular}{|c|c|c|c|c|c|}
\hline Antenatal complication & Adolescent group $(n=243$ ) & Control group $(n=2738)$ & $\mathbf{P}$ & Odds ratio & $95 \% \mathrm{Cl}^{*}$ \\
\hline Preterm delivery & $26(10.7)$ & $128(4.7)$ & $<.001$ & 2.46 & $1.80-3.37$ \\
\hline PPROM** & $7(2.9)$ & $45(1.6)$ & .201 & 1.68 & $0.75-3.76$ \\
\hline Preeclampsia & $21(8.6)$ & $142(5.2)$ & .005 & 2.14 & $1.30-3.51$ \\
\hline Eclampsia & 0 & $2(0.2)$ & - & - & - \\
\hline $\mathrm{FGR}^{* * *}$ & $20(3.4)$ & $71(2.6)$ & .26 & 1.33 & $0.80-2.19$ \\
\hline $\mathrm{GDM}^{* * * *}$ & $2(0.8)$ & $32(1.1)$ & .37 & 0.62 & $0.22-1.77$ \\
\hline Abruption of placenta & $2(0.8)$ & $31(1.1)$ & .23 & 0.41 & $0.80-1.09$ \\
\hline Placenta previa & $1(0.4)$ & $22(0.8)$ & .05 & 0.52 & $0.42-2.23$ \\
\hline
\end{tabular}

${ }^{*} \mathrm{Cl}$ - confidence interval; **PPROM - preterm premature rupture of the membranes; ***FGR - fetal growth restriction; ${ }^{* * * * G D M}$ - gestational diabetes mellitus. Data are expressed as $n(\%)$ except where otherwise noted. The mean difference is significant at the .05 level

group ( $p<0.001)$ and cephalopelvic disproportion (CPD) that is more frequent in the adolescent group $(p=0.005)$. Multiple Logistic Regression Analysis of Antenatal Complications is presented in Table 3. Preeclampsia $(p<0.001)$ and preterm delivery rates $(p=0.005)$ are higher in the study group and the difference is statically significant. There is no statically significant difference between the study and the control group in preterm premature rupture of membranes (PPROM), fetal growth restriction (FGR), gestational diabetes mellitus (GDM) or abruption of placenta.

\section{DISCUSSION}

Antenatal and postnatal complications of pregnancy are more common in adolescence. Incomplete physical and psychological development of the adolescents is the main etiology of pregnancy complications. Comparing to pregnancies of adults population, preterm birth, intrauterine growth retardation, fetal death, abortion, chronic fetal distress, fetal malformation, placental abruption and cesarean or operative birth rate are more frequent in adolescent pregnancies [1-3].

Studies show that perinatal mortality rate in adolescent pregnancy is at $11.2 \%$, which is 1.9 times higher than in non-adolescent (adult) pregnancies [4]. Furthermore, apart from fetal outcomes, maternal adverse outcomes have higher rates as well. Maternal mortality rate, nutrition problems, depression, exploitation and inculpation is observed more frequently in adolescent pregnancies. Economic and social problems of adolescence have an impact on their school life and prevents development of proper ties with social surrounding. Pregnant adolescent women who terminate their pregnancy continue attending school. In contrast, pregnant adolescent women who keep the pregnancy hold up their education or even quit it [5].

Studies show that adolescent pregnancies have a lower cesarean rate compared to non-adolescent pregnancies [5]. 
Also, the second phase of labor is shorter [6]. In our study, cesarean rate is determined in adolescent group to be at $29.2 \%$ and in control group at 34.6\%. Despite higher cesarean rate in the control group we didn't find the difference to be statically significant.

A literature review indicates that the neonatal outcomes in adolescent pregnancies are similar to non-adolescent pregnancies. The overall rate of congenital abnormality, newborn intensive care requirement or neonatal death is very low $[2,6,7]$. In our study, Apgar score and newborn intensive care requirement is also very low and no neonatal death is recorded.

According to literature, preterm birth is seen frequently in adolescent pregnancies. Similarly, our study preterm birth rate ( $\leq 37$ weeks) is found to be relatively high $(p<0.001)$ $[2,6-8]$.

When it comes to operative delivery rates in adolescent pregnancies, the literature is inconclusive. Two studies found the operative delivery rate to be high [1, 2]. On the other hand, another study found it to be relatively lower [8]. In our study there is no operative delivery (with use of forceps or vacuum) made because of clinicians preferring cesarean section.

In our study unplanned pregnancy rate is higher in adolescent group (69.6\%) compared to control. Unfortunately, this shows that the use of contraception in adolescent group is low. In Turkey, in order to examine physically a patient under the age of 18 , parent consent is required. This is the reason why adolescent pregnant women don't attend family planning clinics to learn about contraception. Awareness remains low since some cases of pregnancy are realized when it is too late to terminate pregnancy (due to advanced gestation). One study observed that a parental consent mandate is behind the great amount of decrease in teenagers' attendance at family planning centers but it didn't lead to an increase in underage pregnancies [9].

In developed countries schools run lessons for pupils to give them information about sexuality, reproduction and contraception, which is a practice we don't have in our country. Such sexual education raises awareness in adolescents. Moreover, the use of oral contraceptives has decreased the pregnancy rates, so did other contraceptive techniques while last resort solution in form of abortion remains available and legal $[1,10]$. In contrast, in our country or similar underdeveloped countries, adolescents who have sex or get pregnant are forced to marriage because of religious reasons, traditions or family/social pressure.

In one study the adolescents have declared that $64.1 \%$ of them had at least 1 or more $(\geq 1)$ sexual intercourse and $49.3 \%$ of them had a sexual intercourse with at least 1 or more partners in last 3 months. Unfortunately, it was admitted that only $53 \%$ of them have used condom during last sexual intercourse, while only $32.2 \%$ of adolescent women were using oral contraceptives, intrauterine device, implant, patch or ring [11].

Psychological problems arise not only from birth and postpartum period but also from rape $[1,10]$. Although it would be possible to obtain a legal abortion in underage pregnancy or any pregnancy in effect of rape by means of prosecution and court order, such possibility will remain usually unexploited if individual and family education is not provided.

Mode of delivery in underage pregnancies is characterized by high operative births since often it is necessary due to problems related with patient compliance. We obtained a similar result in our study. Such issue should be interpreted and handled as a social issue and even though we can't solve it completely, we shall intend to minimize it through social education.

\section{CONCLUSIONS}

Underage pregnancies $(<18)$ not only cause medical problems but also isolate adolescent individuals from the community by sociocultural ostracism. Although means of law attempt to prevent such situations, the challenge remains to decrease their frequency. We postulate the best means for that would be social education so the community is informed about the potential adverse outcomes of adolescent pregnancy. The education should be multichannel and include schools, press institutions, public service broadcasting and organization of free seminars.

\section{Conflict of interest}

Authors have declared that no competing interests exist.

\section{REFERENCES}

1. Ozer E, Nacar MC, Yildirim A, et al. Underage mothers in Turkey. Med Sci Monit. 2014; 20: 582-586, doi: 10.12659/MSM.890341, indexed in Pubmed: 24714663.

2. Raatikainen K, Heiskanen N, Verkasalo PK, et al. Good outcome of teenage pregnancies in high-quality maternity care. Eur J Public Health. 2006; 16(2): 157-161, doi: 10.1093/eurpub/cki158, indexed in Pubmed: 16141302.

3. Pal A, Gupta KB, Randhawa I. Adolescent pregnancy: a high risk group. J Indian Med Assoc. 1997; 95(5): 127-128, indexed in Pubmed: 9357255.

4. Porozhanova V, Bozhionova S, Velkova A, et al. [The perinatal results in underage mothers]. Akush Ginekol (Sofiia). 1995; 34(3): 12-14, indexed in Pubmed: 8743836.

5. Curtis HA, Lawrence CJ, Tripp JH. Teenage sexual intercourse and pregnancy. Arch Dis Child. 1988; 63(4): 373-379, indexed in Pubmed: 3365006.

6. Chantrapanichkul $\mathrm{P}$, Chawanpaiboon S. Adverse pregnancy outcomes in cases involving extremely young maternal age. Int J Gynaecol Obstet. 2013; 120(2): 160-164, doi: 10.1016/j.ijgo.2012.08.024, indexed in Pubmed: 23182803.

7. Kawakita T, Wilson K, Grantz KL, et al. Adverse Maternal and Neonatal Outcomes in Adolescent Pregnancy. J Pediatr Adolesc Gynecol. 2016; 29(2): 130-136, doi: 10.1016/j.jpag.2015.08.006, indexed in Pubmed: 26327561.

8. Debras E, Revaux A, Bricou A, et al. [Obstetric and neonatal outcomes of adolescent pregnancies: a cohort study in a hospital in Seine-Saint-De- 
nis France]. Gynecol Obstet Fertil. 2014; 42(9): 579-584, doi: 10.1016/j. gyobfe.2014.04.012, indexed in Pubmed: 24996878.

9. Girma S, Paton D. Does parental consent for birth control affect underage pregnancy rates? The case of Texas. Demography. 2013; 50(6): 2105-2128, doi: 10.1007/s13524-013-0225-1, indexed in Pubmed: 23765262.
10. Kükner S, Vicdan K, Dabakoğlu T, et al. [Sexual education levels of adolescents]. Journal of Turkish Society of Obstetric and Gynecology. 1993; 7: 138-144

11. Gibson EJ. All Adolescents Deserve Routine Conversations About Sexual Activity and Pregnancy Prevention. Pediatrics. 2016; 137(1), doi: 10.1542/peds.2015-3826, indexed in Pubmed: 26676051. 